\title{
Study of Serum Lipid Profile in Type-2 Diabetes Mellitus Patients
}

\author{
Vijaya Mohan ${ }^{1}$, Vishwanath VN ${ }^{1}$ \\ ${ }^{1}$ Associate Professor, Department of General Medicine, KBNIMS, Gulbarga, Karnataka.
}

\section{Abstract}

Background: Dyslipidemia may cause or exacerbate diabetic retinopathy and nephropathy and alterations in the coagulation-fibrnolytic system, changes in membrane permeability, damage to endothelial cells and increased atherosclerosis. Serum triglycerides and all types of lipoproteins are affected and this leads to increase morbidity and mortality in type 2 diabetic patients. Subjects and Methods: A total of 100 with type-2 diabetes mellitus irrespective of duration of diabetes in the age group of 35-80 years formed the study subjects. A pre-structural proforma will be used to collect baseline date detailed clinical history with clinical examination and relevant investigation will be done on participating individuals. Results: During our study we randomly selected 100 Diabetes mellitus-type-2 patients visiting OPD or admitted in the department of Medicine at our institution. Out of $100 \mathrm{DM}$ patients, 61 were Males and 39 were Females. The Mean age of patients in our study was $57.29 \pm 56.55 \mathrm{mg} / \mathrm{dl}$ and mean PPBS was $252 \pm 73.76 \mathrm{mg} / \mathrm{dl}$. Conclusion: This study shows significant increasing levels of TG, TC, LDl-C, and Vdl-C and significant decrease in level of HDL-C has the severity of diabetes.

Keywords: Serum Lipid Profile, Type-2 Diabetes Mellitus,Dyslipidemia.

Corresponding Author: Dr. Vishwanath VN, Associate Professor, Department of General Medicine, KBNIMS, Gulbarga, Karnataka.

Received: June 2019

Accepted: June 2019

\section{Introduction}

Type 2 diabetes mellitus is the most prevalent form of diabetes worldwide. In western countries most of the cases are obese. The scenario may be different in certain parts of India. Various studies have shown in India that high prevalence of lean type 2 diabetes mellitus with a body mass index $<19 \mathrm{~kg} / \mathrm{m}^{[1]}$

Dyslipidemia is an important component observed in type 2 diabetes patients. Patients having one or more parameters (TG, HDL cholesterol, or LDL cholesterol) outside the gargets will be considered to have dyslipidemia which includes serum cholesterol $>240 \mathrm{mg} / \mathrm{dl}$ and TG $>160 \mathrm{mg} / \mathrm{dl}$ and LDL $>130 \mathrm{mg} / \mathrm{dl}$ and HDL-C $<40 \mathrm{mg} / \mathrm{dl} .{ }^{[2]}$

Dyslipidemia may cause or exacerbate diabetic retinopathy and nephropathy and alterations in the coagulationfibrnolytic system, changes in membrane permeability, damage to endothelial cells and increased atherosclerosis.

Serum triglycerides and all types of lipoproteins are affected and this leads to increase morbidity and mortality in type 2 diabetic patients. ${ }^{[3]}$

Dyslipidemia has been noted to play an integral role in the pathogenesis and progression of micro and macro vascular complications in diabetes mellitus patients.

Dyslipidemia is one of the key risk factors for cardiovascular dieses in diabetes mellitus.

TG/HDL-C ratio was associated with an increased incidence of microvascular complications in individuals with type 2 diabetes mellitus without prior cardiovascular disease, independently of several potential confounders. ${ }^{[4,5]}$
Aim of this study is to study the serum lipid profile in type 2 diabetes mellitus patients.

\section{Subjects and Methods}

A total of 100 with type- 2 diabetes mellitus irrespective of duration of diabetes in the age group of 35-80 years formed the study subjects.

\section{Method of collection of data}

A pre-structural proforma will be used to collect baseline date detailed clinical history with clinical examination and relevant investigation will be done on participating individuals.

\section{Inclusion Criteria}

- Patients with type 2 diabetes mellitus

\section{Exclusion Criteria}

- Patient with liver disorders

- Patients with $\mathrm{BMI}>30 \mathrm{Kg} / \mathrm{m} 2$

- Patients on lipid lowering agents (statins, fibrates, etc.)

- Patients on treatment with medications which alter lipid profile

- Patients with age $<20$ years and $>80$ years.

TM Turbodyne HbA1c is a turbidimetric immunoassay for direct determination of $\mathrm{HbAlc}$ and is based on the principle of agglutination reaction. The test specimen after treatment 
with Hemolysing solution is allowed to react with latex reagent $(\mathrm{RI})$.

Total $\mathrm{Hb}$ and $\mathrm{HbAlc}$ bind with same affinity to latex particles. The amount of binding is proportional to the relative concentration of both substances in blood. The reaction mixture is then allowed to react with mouse anti human Hba1c monoclonal antibody and goat anti-mouse human $\lg \mathrm{G}(\mathrm{R} 2)$ resulting in agglutination reaction that is measured at $-650 \mathrm{~nm}$. The increase in turbidity corresponds to the concentration of $\mathrm{HbAlc}$ in the test specimen.

\section{Results}

During our study we randomly selected 100 Diabetes mellitus-type-2 patients visiting OPD or admitted in the department of Medicine at our institution. Out of 100 DM patients, 61 were Males and 39 were Females. The Mean age of patients in our study was $57.29 \pm 56.55 \mathrm{mg} / \mathrm{dl}$ and mean PPBS was $252 \pm 73.76 \mathrm{mg} / \mathrm{dl}$.

Table 1: Distribution of Gender with type-2 diabetes

\begin{tabular}{|l|l|l|}
\hline Sex $(\mathbf{n}=\mathbf{1 0 0})$ & Frequency & Percent \\
\hline Female & 39 & 39.0 \\
\hline Male & 61 & 61.0 \\
\hline Total & 100 & 100. \\
\hline
\end{tabular}

Table 2: Distribution of Age with type-2 diabetes

\begin{tabular}{|l|l|l|}
\hline Age (Years) & Frequency & Percent \\
\hline$<+35$ & 3 & 3.0 \\
\hline $36-45$ & 10 & 10.0 \\
\hline $46-55$ & 35 & 35.0 \\
\hline $56-65$ & 36 & 36.0 \\
\hline $66+$ & 16 & 16.0 \\
\hline Total & 100 & 100.0 \\
\hline
\end{tabular}

\begin{tabular}{|l|l|l|}
\hline Table 3: HBA1C Distribution & \\
\hline HBA1C & Frequency & Percent \\
\hline$<+5.0$ & 1 & 1.0 \\
\hline $5.1-7.0$ & 29 & 29.0 \\
\hline $7.1-9.0$ & 63 & 63.0 \\
\hline $9.1+$ & 7 & 7.0 \\
\hline $9.1+$ & 7 & 7.0 \\
\hline Total & 100 & 100.0 \\
\hline
\end{tabular}

Table 4: Mean values of lipid parameters in our study

\begin{tabular}{|l|l|}
\hline Lipid parameter & Man \pm SD \\
\hline TC & $196.97 \pm 48.18$ \\
\hline LDL & $122.75+49.36$ \\
\hline TG & $160.93+56.21$ \\
\hline HDL & $39.64 \pm 10.50$ \\
\hline VLDL & $32.21 \pm 11.32$ \\
\hline
\end{tabular}

\section{Discussion}

Type 2 DM has emerged one of the most common causes of dyslipidemia vascular complications are believed to be critical for prognosis of DM and there development, in turn, is believed to depend on several factors such as duration, degree of control, and dyslipidemia in diabetes. It is been found that type $2 \mathrm{DM}$ suffer from dyslipidemia in tune leading to various vascular complications.

Several workers in India have reported that in the incidence of diabetes is greater in male then females. In our study, it is observed that $61 \%$ were males $39 \%$ were females.

Retinopathy was seen in $75 \%$ of the study group. According to the American diabetic association, at the 10 and 15 years the diabetic retinopathy was $58 \%$ and $18 \%$, respectively. In our study, the incidence neuropathy was $40 \%$.

This study has shown that TG, TC, LDL-c, and VLDL-C, the lipid profile are higher significantly in diabetes than and HDL-C was significantly lower in diabetics. According Fredrick et al. 1994, Michel et al. 1989, in Type 2 DM there is significant elevation of TG, VLDL-C, and decreasing in HDL-C. Our study has shown similar results except for TC, LDL-C which are significantly elevated.

The reasons for increasing Tc LDL-C are increasing in the incidence of the obesity, sedentary life lack of physical activity, the diet, and risk factors like hypertension.

In our study, severity of diabetes was classified according to the levels of HbA1c a better marker of glucose levels than FBS and PPBS, Here, more than 50\% of the patient had more than 8. And also this study shows an significant increasing levels of TG, TC, LDl-C, and Vdl-C and significant decrease in level of HDL-C has the severity of diabetes or $\mathrm{HbAlc}$ increased similar results were observed Ahuja et al. Din ; Gossion et al. ; Pfeifer et al, found similar relationship between $\mathrm{HbA} 1 \mathrm{c}$ and various lipid fraction. ${ }^{[6-8]}$

\section{Conclusion}

- In this study group, the average duration of diabetes was 8 years. Of 100 patients, $61 \%$ were males and 39\% were females. The average duration of diabetes was 8 years.

- The mean values of the entire lipid fraction TG, TC, LDL-C, and VLDL-C, were statistically significantly higher in diabetics.

\section{References}

1. Punyakrit Deb Barma, Salam Ranabir, Lallan Prasad, and thanglamPremachandsingh, clinical and biochemical profile of lean type 2 diabetes mellitus. Indian J endocrinolMetab. 2011; 15 (5): 40-3.

2. Agrawal RP, Sharma P, Pal M., Kochar A, Kochar DK. Magnitude of dyslipidemia and its association with mocro and macro vascular complications in type 2 diabetes: A hospital based study from Bikaner. Diabetes Res Clinpract 2006; 73(2):211-4.

3. Mistra A, Kumar S, Kishore Vikram N, Kumar A. The role of lipids in the developemtn of diabetic

4. Amin-U1-Haq, et al. Pattern of Lipid Profile in type 2 diabetes mellitus patients. JPMI 2006;20(4)"366-9

5. Jisieike- Onuigbo NN, Unuigbe EI, Oguejiofor CO. Dyslipidemias in ype 2 diabetes mellitus patients in Nnewi south-East Nigeria. Ann Afr Ned, 2011; 10(4);285-9. microvascular complications implications for therapy. Am J Cardiovase: Drugs. 2003;3(5):325-38.

6. Chehade JM, Gladysz M, Mooradian AD. Dyslipidemia in type 2 diabetes: prevalence, pathophysiology, and management, Drugs. 2013;73(4):327-39.

7. Zoppini G, negri c, Stoico V, Casati S, Pichiri I, Bonora E. Triglyceride-high-density lipoprotein cholesterol in associated with microvascular complications in type 2 diabetes mellitus. Metabolism 2012:61(1):22-9.

8. Mahato RV, Gyawali P, Raut PP, Regmi P, Khelanand Ps, Dipendra RP, Gyawali P. Association between glycaemic control and serum lipid profile in type 2 diabetc patients: glycatedhaemoglobin as a dual biomarker. Biomed Res. 20111;22(3);375-380.15. 
Copyright: () the author(s), 2019. It is an open-access article distributed under the terms of the Creative Commons Attribution License (CC BY 4.0), which permits authors to retain ownership of the copyright for their content, and allow anyone to download, reuse, reprint, modify, distribute and/or copy the content as long as the original authors and source are cited.

How to cite this article: Mohan V, Vishwanath VN. Study of Serum Lipid Profile in Type-2 Diabetes Mellitus Patients. Acad. J Med. 2019;2(1):15-17.

DOI: dx.doi.org/10.21276/ajm.2019.2.1.5

Source of Support: Nil, Conflict of Interest: None declared. 